\title{
Natural variation of physiological traits, molecular markers, and chlorophyll catabolic genes associated with heat tolerance in perennial ryegrass accessions
}

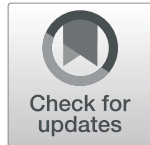

Jing Zhang ${ }^{1}$, Hui Li ${ }^{1}$, Yiwei Jiang ${ }^{2}$, Huibin $\mathrm{Li}^{3}$, Zhipeng Zhang ${ }^{4}$, Zhipeng $X u^{1}$, Bin Xu ${ }^{1 *}$ (1) and Bingru Huang ${ }^{5}$

\begin{abstract}
Background: Identification of genetic diversity in heat tolerance and associated traits is of great importance for improving heat tolerance in cool-season grass species. The objectives of this study were to determine genetic variations in heat tolerance associated with phenotypic and physiological traits and to identify molecular markers associated with heat tolerance in a diverse collection of perennial ryegrass (Lolium perenne L.).

Results: Plants of 98 accessions were subjected to heat stress $\left(35 / 30^{\circ} \mathrm{C}\right.$, day/night) or optimal growth temperature $\left(25 / 20^{\circ} \mathrm{C}\right)$ for $24 \mathrm{~d}$ in growth chambers. Overall heat tolerance of those accessions was ranked by principal component analysis (PCA) based on eight phenotypic and physiological traits. Among these traits, electrolyte leakage (EL), chlorophyll content (Chl), relative water content (RWC) had high correlation coefficients $(-0.858,0.769$, and 0.764 , respectively) with the PCA ranking of heat tolerance. We also found expression levels of four Chl catabolic genes (CCGS), including LPNYC1, LPNOL, LpSGR, and LPPPH, were significant higher in heat sensitive ryegrass accessions then heat tolerant ones under heat stress. Furthermore, 66 pairs of simple sequence repeat (SSR) markers were used to perform association analysis based on the PCA result. The population structure of ryegrass can be grouped into three clusters, and accessions in cluster $C$ were relatively more heat tolerant than those in cluster A and B. SSR markers significantly associated with above-mentioned traits were identified $\left(R^{2}>0.05\right.$, $p<0.01$ )., including two pairs of markers located on chromosome 4 in association with Chl content and another four pairs of markers in association with EL.

Conclusion: The result not only identified useful physiological parameters, including EL, Chl content, and RWC, and their associated SSR markers for heat-tolerance breeding of perennial ryegrass, but also highlighted the involvement of Chl catabolism in ryegrass heat tolerance. Such knowledge is of significance for heat-tolerance breeding and heat tolerance mechanisms in perennial ryegrass as well as in other cool-season grass species.
\end{abstract}

Keywords: Perennial ryegrass, Leaf senescence, Heat tolerance, SSR, Genetic diversity

\footnotetext{
* Correspondence: binxu@njau.edu.cn

${ }^{1}$ College of Agro-grassland Science, Nanjing Agricultural University, Nanjing 210095, P.R. China

Full list of author information is available at the end of the article
}

C C The Author(s). 2020 Open Access This article is licensed under a Creative Commons Attribution 4.0 International License, which permits use, sharing, adaptation, distribution and reproduction in any medium or format, as long as you give appropriate credit to the original author(s) and the source, provide a link to the Creative Commons licence, and indicate if changes were made. The images or other third party material in this article are included in the article's Creative Commons licence, unless indicated otherwise in a credit line to the material. If material is not included in the article's Creative Commons licence and your intended use is not permitted by statutory regulation or exceeds the permitted use, you will need to obtain permission directly from the copyright holder. To view a copy of this licence, visit http://creativecommons.org/licenses/by/4.0/ The Creative Commons Public Domain Dedication waiver (http://creativecommons.org/publicdomain/zero/1.0/) applies to the data made available in this article, unless otherwise stated in a credit line to the data. 


\section{Background}

Improving heat tolerance is among major efforts of breeding improvement in cool-season grass species [1]. The available germplasm collections with large genetic variability and a wide range of heat-tolerance levels are important breeding materials for grass breeding program [2-4]. To make good use of the germplasm pool, it is essential to understand their genetic diversity as well as physiological and molecular factors underlying heat stress tolerance for the breeding of heat-tolerant cultivars.

Understanding the genetic structure and phenotypic diversity using phenotypic traits and molecular markers is the basis of parental selection for trait improvement in breeding, such as for heat tolerance [5-7]. Phenotypic analysis focuses on growth, morphological, and physiological parameters among germplasm and provides information regarding genetic diversity, homogeneity, and stability [7, 8]. Since abiotic stress adversely affect a multitude of morphological and physiological processes, a number of distinct morphological and physiological characteristics have been used as marker traits to evaluate genetic variations in plant stress tolerance, such as root activity (RA), photochemical efficiency $(\mathrm{Fv} / \mathrm{Fm})$, photosynthetic rate $(\mathrm{Pn})$, water use efficiency (WUE), chlorophyll (Chl) content, and leaf relative water content (RWC) [7, 9-11]. The selection of germplasm based on physiological traits is an efficient approach in breeding for improved stress tolerance in various crop species [7, 12-14]. In the case of cool-season grass breeding for heat tolerance, such information of closely associated physiological trait(s) to heat tolerance is still largely unclear.

Molecular markers linked to phenotypic and physiological traits have been developed to understand the genetic diversity and to predict desirable traits of a given germplasm or breeding materials [7]. To date, molecular makers associated with several important agronomic traits of perennial ryegrass have been developed, including crown rust resistance [15], drought tolerance [16], winter survival and spring re-growth [17], submergence [18], and salinity tolerance (Tang et al., 2013). For examples, Yu et al. (2011) evaluated the submergence tolerance of 99 diverse perennial ryegrass accessions using 109 simple sequence repeat (SSR) markers, and identified 15 pairs of SSR markers associated with alterations of several morphological and physiological traits (e.g. leaf color, Fv/ Fm, maximum plant height, and relative growth rate) [18]. Tang et al. (2013) analyzed the genetic diversity of 56 perennial ryegrass accessions of different origins using 66 SSR makers, and found that population structure influenced phenotypic traits, and allelic variation in $L p N H X 1$ might explain the variation of salinity tolerance of perennial ryegrass [19]. Yet, molecular markers associated with heat-tolerant are to be developed in perennial cool-season grass species.

Perennial ryegrass (Lolium perenne L.), native to Europe, Asia, and Northern Africa, is the most widely cultivated perennial cool-season grass in the temperate regions worldwide for its turf and forage purposes [20, 21]. Perennial ryegrass is considered as a heat-sensitive grass species, and the established ryegrass sward is often challenged by heat stress. Despite of the diversity of perennial ryegrass to various other stresses and diseases, as discussed above, neither the diversity of heat tolerance among perennial ryegrass germplasm collections was quantitatively measured, nor the molecular markers associated with heat tolerance been developed for this species. The objectives of this study were to understand physiological traits and to identify molecular markers associated with heat tolerance in a diverse collection of perennial ryegrass. Such knowledge will be valuable for heat-tolerant breeding in perennial ryegrass as well as other cool-season grass species.

\section{Results}

Evaluation of heat tolerance in 98 accessions of perennial ryegrass

A total of seven physiological traits (WUE, Pn, RA, Chl content, RWC, EL, and $\mathrm{Fv} / \mathrm{Fm}$ ) and three phenotypic traits (TQ, LW, and $\mathrm{PH}$ ) were used to evaluate heat tolerance of 98 perennial ryegrass accessions (Supplementary materials 1). Effects of heat stress treatment, genotype, and interaction of these two factors were all significant $(p \leq 0.05)$ for WUE, Pn, RA, Chl, RWC, Fv/ Fm, EL, and TQ. Only genotypic variations were significant for LW and PH (Table 1).

The data for physiological and phenotypic traits of 98 accessions exposed to heat stress or optimum temperature (control) conditions were used to plot a heatmap (Fig. 1),

Table 1 Summary of variance for the effects of treatments, genotypes, and the interaction between temperature and genotype on photochemical efficiency (Fv/Fm), chlorophyll content (Chl), photosynthesis rate (Pn), water use efficiency (WUE), electrolyte leakage (EL), leaf relative water content (RWC), root activity (RA), turf quality (TQ), leaf width (LW), and plant height (PH) across 98 perennial ryegrass accessions with the data of 24 days treatment

\begin{tabular}{|c|c|c|c|c|c|c|c|c|c|c|}
\hline & \multicolumn{7}{|c|}{ Physiological traits } & \multicolumn{3}{|c|}{ Morphological traits } \\
\hline & $\mathrm{Fv} / \mathrm{Fm}$ & Chl & Pn & WUE & EL & RWC & $\mathrm{RA}$ & $\overline{T Q}$ & LW & $\mathrm{PH}$ \\
\hline Treatment & $* * *$ & $* * *$ & $* * *$ & $* * *$ & $* * *$ & $* * *$ & $* * *$ & *** & NS & NS \\
\hline Genotype & * & $* *$ & $* *$ & $* *$ & * & $* *$ & $* *$ & $* *$ & * & $* *$ \\
\hline Treatment X Genotype & $* *$ & $* * *$ & $* * *$ & $* * *$ & $* *$ & $* * *$ & $* *$ & $* * *$ & NS & NS \\
\hline
\end{tabular}




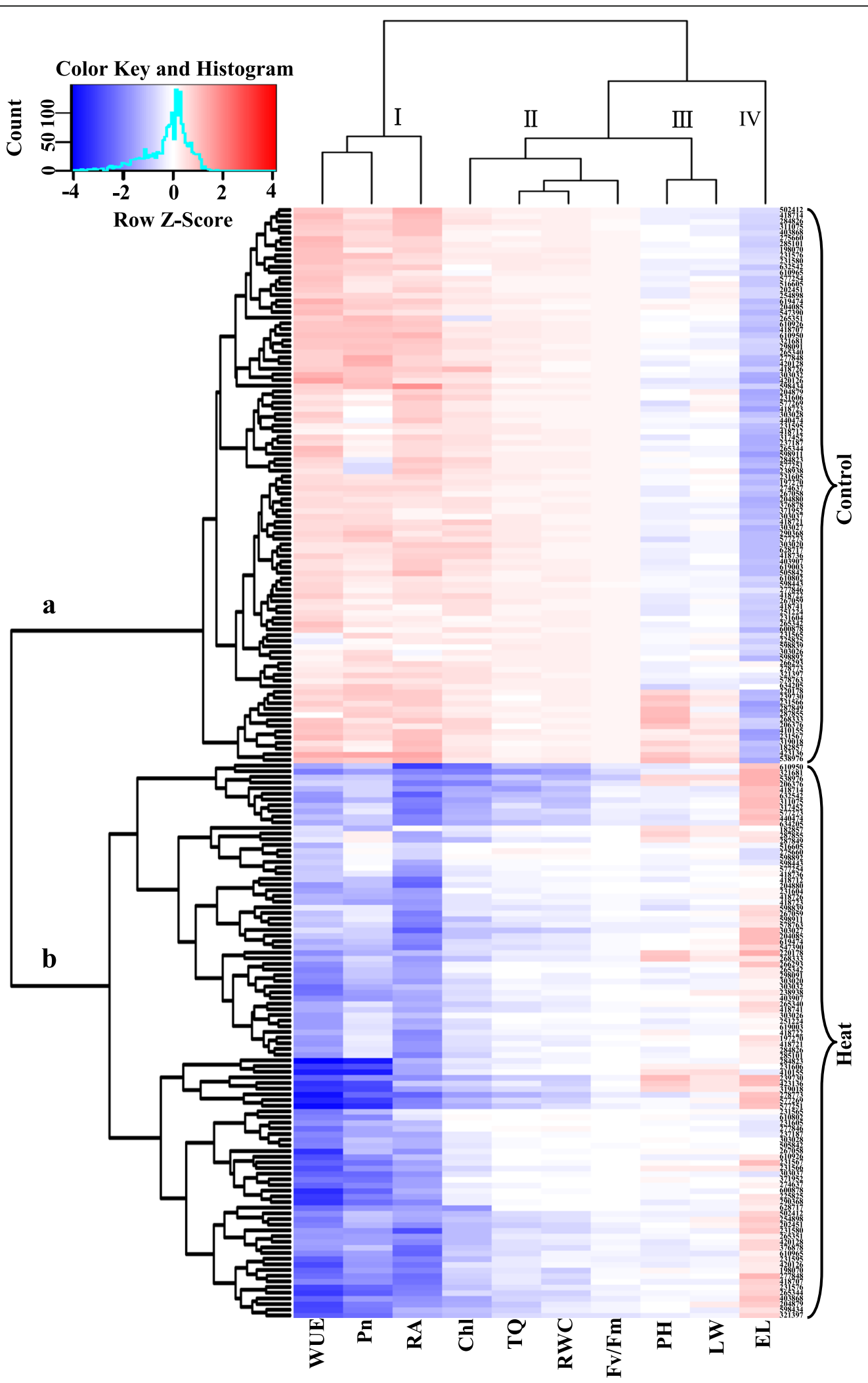

Fig. 1 Heatmap and hierarchical clustering for physiological and morphological parameters under control and heat stress conditions in 98 ryegrass accessions after $24 \mathrm{~d}$ of treatment. Abbreviations: WUE, water use efficiency; Pn, photosynthesis rate; RA, root activity; Chl, chlorophyll content; RWC, leaf relative water content; Fv/Fm, photochemical efficiency; PH, maximum plant height; LW, leaf width 
in which the hierarchical cluster was clearly grouped into two distinct sub-clusters: accessions under the control condition (sub-cluster ' $a$ ') and those under the heat stress (sub-cluster 'b' as shown in Fig. 1). Accordingly, ten traits used to evaluate ryegrass heat tolerance were grouped into four sub-clusters: sub-cluster I included WUE, Pn, and RA, where their values were lower under heat stress than those under control condition; sub-cluster II included Chl content, TQ, RWC, and Fv/Fm, which values were also lower under heat stress; sub-cluster III, including the two morphological traits ( $\mathrm{PH}$ and $\mathrm{LW}$ ), did not show consistent alteration under the two growth conditions; and subcluster IV, only consisted of one trait (EL), had higher values under heat stress (Fig. 1). Therefore, eight traits, excluding LW and PH, were used to evaluate ryegrass heat tolerance in the following analyses.

\section{Ranking of overall heat tolerance for 98 accessions of perennial ryegrass}

The PCA analysis of variations in heat tolerance of 98 accessions based on HSI identified a total of eight principal components (PC 1-8). The sum of the first PCs (PC1 to PC4) explained $88.45 \%$ of the total variance, among which the 1st and 2nd PCs were the major ones explaining 52.67 and $20.37 \%$ of the variance among 98 ryegrass accessions, respectively (Supplementary Table 1). Based on the PCA result, the following formulas were developed (details of the formula were shown in Supplementary Table 2): $\mathrm{PC} 1$ value $=0.897 \times \mathrm{TQ}+0.766 \times \mathrm{Fv} /$ $\mathrm{Fm}+0.858 \times \mathrm{Chl}$ content $+0.373 \times \mathrm{Pn}+0.244 \times \mathrm{WUE}+$ $(-0.691) \times \mathrm{EL}+0.891 \times \mathrm{RWC}+0.785 \times \mathrm{RA} ; \quad$ and $\mathrm{PC} 2$ value $=(-0.199) \times \mathrm{TQ}+(-0.311) \times \mathrm{Fv} / \mathrm{Fm}+(-0.055) \times$ Chl content $+0.809 \times \mathrm{Pn}+0.896 \times \mathrm{WUE}+(-0.043) \times \mathrm{EL}$ $+(-0.180) \times \mathrm{RWC}+0.040 \times \mathrm{RA}$; (3) $\mathrm{PC} 3$ value $=0.196 \times$ $\mathrm{TQ}+0.413 \times \mathrm{Fv} / \mathrm{Fm}+(-0.119) \times \mathrm{Chl}$ content $+0.233 \times$ $\mathrm{Pn}+0.033 \times \mathrm{WUE}+0.566 \times \mathrm{EL}+0.095 \times \mathrm{RWC}+(-$ $0.227) \times \mathrm{RA}$; and $\mathrm{PC} 4$ value $=0.031 \times \mathrm{TQ}+(-0.125) \times$ $\mathrm{Fv} / \mathrm{Fm}+0.219 \times \mathrm{Chl}$ content $+(-0.220) \times \mathrm{Pn}+0.130 \times$ $\mathrm{WUE}+0.431 \times \mathrm{EL}+(-0.166) \times \mathrm{RWC}+0.480 \times \mathrm{RA}$, and PCA rank value $=(52.67 \% \times \mathrm{PC} 1)+(20.37 \% \times \mathrm{PC} 2)+$ $(8.25 \% \times$ PC3 $)+(7.17 \% \times$ PC4 $)$.

According to PCA results, we clustered 98 ryegrass accessions into two groups:Group-i consisted of 49 accessions with PCA rank value at the top half of all accessions, while the rest 49 accessions clustered to group-ii (Fig. 2). Heat tolerance of 98 accessions were

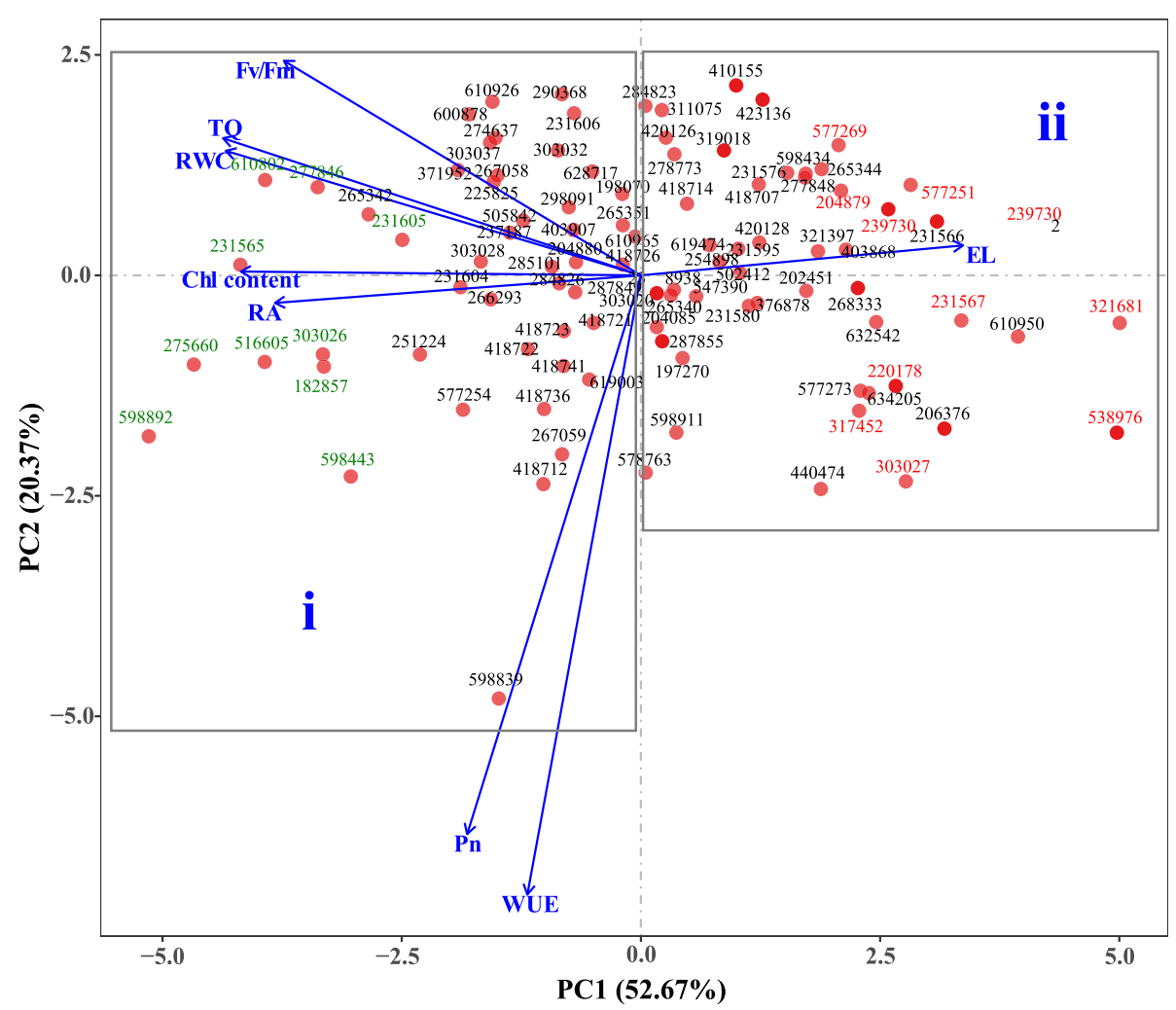

Fig. 2 Principal component analysis biplot of the heat stress index (HSI) of 98 ryegrass accessions. Arrows represent physiological and morphological traits with various lengths based on the impact of each trait on the separation of accessions. Accessions marked with green color in group i and red color in group ii are the ten most and least heat tolerant genotypes, respectively. Abbreviations: WUE, water use efficiency; Pn, photosynthesis rate; RA, root activity; Chl, chlorophyll content; RWC, leaf relative water content; FV/Fm, photochemical efficiency; $\mathrm{PH}$, maximum plant height; LW, leaf width 
then ranked according to their PCA ranking values based on the HIS of eight parameters (WUE, Pn, RA, Chl content, RWC, and Fv/Fm, EL, and TQ), with accessions 275,660, 598,892, 277,846, 516,605, and 598,443 ranked as the top five accessions for heat tolerance and 538,976, 321,681, 317,452, 239,730, and 303,027 ranked as the most heat-sensitive accessions (Table 2). Phenotypes of the top and least five heat tolerant ryegrass accessions were shown in Fig. 3, that plants of the toprated accessions had more green leaves or greener leaves while the most heat-sensitive accessions had more yellow or less green leaves.

To understand contributions of different traits to heat tolerance in perennial ryegrass, the relationships between PCA ranking based on HSI for overall heat tolerance and each physiological/phenotypic trait was determined using Pearson correlation analysis. As shown in Table 3, the PCA ranking was significantly correlated with all eight traits used in the evaluation $(p \leq 0.05)$, among which ranking values of PCA and EL had the largest correlation coefficient $(r=-0.858)$. And ranking values of Chl content, RWC, and TQ also showed high correlation coefficients with those of PCA $(r=0.769$, 0.764 , and 0.744 , respectively). Values of Pn and WUE had low correlation coefficients with those of PCA $(r=$ 0.306 and -0.216 , respectively), although their correlations were statistically significant as well $(p \leq 0.05)$ (Table 3).

Transcript levels of chlorophyll-catabolic genes correlated to heat tolerance in perennial ryegrass

Results of Pearson correlation analysis indicated that heat tolerance PCA ranking values and $\mathrm{Chl}$ content had the larger correlation coefficient $(r=0.769$, Table 3$)$, indicating leaf senescence characterized by Chl loss was mostly associated with overall heat tolerance in perennial ryegrass. To confirm the contribution of Chl catabolism to heat-tolerant accessions of perennial ryegrass, we further analyzed whether there was a correlation between transcription of four Chl catabolic genes (CCGs, including $L p N Y C 1$, $L p N O L, L p S G R$, and $L p P P H$ ) and the PCA ranking values of heat tolerance of 98 ryegrass accessions. As shown in Fig. 4, relative expression levels of CCGs were significantly higher in heat-sensitive accessions than those in heat-tolerant accessions.

\section{Classification of 98 accessions of perennial ryegrass based on SSR markers}

Genotypic diversity within the selected ryegrass accessions was estimated using 66 pairs of SSR molecular markers. The SSR analysis yielded 864 polymorphic bands in total, with an average of 13 and a range of 3 to 26 bands per pair of primers (Supplementary material 2). The resultant polymorphism information content (PIC) values varied from 0.16 to 0.93 , with an average of 0.70 ; while the gene diversity index $(\mathrm{Di})$ values ranged 0.16 to 0.94 , with an average of 0.72 (Supplementary materials 2 ), confirming that the selected accessions represented a diverse genetic pool of perennial ryegrass germplasm. An N-J dendrogram was constructed based on the SSR results, clustering the 98 ryegrass accessions into three groups: Cluster A, B, and C consisting of 14, 10, and 74 ryegrass accessions, respectively (Fig. 5).

Values of PCA ranking of heat tolerance and physiological traits were averaged across ryegrass accessions in each phylogenetic cluster (Table 4), and the results showed that averaged PCA ranking values of accessions in cluster $C$ (61.67) were significantly higher than those in clusters A and B (2.65 and 7.89, respectively), suggesting that accessions in clusters $\mathrm{A}$ and $\mathrm{B}$ were less heat tolerant than those in cluster C. Similar difference was also observed for Chl content, WUE, EL, and RA for genotype ranking of heat tolerance in each phylogenetic cluster (Table 4).

\section{SSR markers associated with physiological traits in heat tolerance}

The associations between the 66 SSR markers and the seven physiological traits were further analyzed using a general linear model (GLM) in TASSEL. As shown in Fig. 6 and Table 5, a total of 34 associations were identified between the SSR markers and the relative values of Chl content, Fv/Fm, Pn, WUE, EL, and RA at $R^{2}>0.05$ $(p<0.01)$. We found that two markers M144 and rv0941, located on chromosome 4, were associated with Chl content. The markers Lp165, rv0941, DLF008, B3C10, B3B8, and B5E1, located on chromosomes 3, 4, 5 , and 7 , were associated with $\mathrm{Fv} / \mathrm{Fm}$. The marker rv0985-1, located on chromosome 6, was associated with Pn. Thirteen markers, including PRG, PR10, M4213, 25ca1, LPSSRH01A07, rv0985-1, rv0005, rv1133, LPSSRH02C11, rv0663, B3B7, LpHCA16B2, and PR37, located on chromosomes 1, 3, 4, 6, and 7, were associated with WUE. The markers M844, LPSSRH01A07, B3B7, B1A10, LpSSR100, LP194, rv0757, and LPSS $\mathrm{RH} 02 \mathrm{C} 11$, located on chromosomes 1,3 , and 5, were associated with RA. The markers LM15, LPSSRH01H06, rye012, and LpHCA17C6 were associated with EL. No association was identified between SSR markers and TQ or RWC (Fig. 6).

\section{Discussion}

Plant heat tolerance is a complex trait that could be attributed by many phenotypic and physiological factors, including those parameters examined in this study, such as Fv/Fm, Pn, Chl content, WUE, and RWC, and root activity $[9,10,22-25]$. PCA is one effective strategy to integrate many factors reflecting facets of a complex trait 
Table 2 The four major components (PC1, PC2, PC3, and PC4) and PCA ranking of each ryegrass genotypes based on turf quality (TQ), photochemical efficiency (Fv/Fm), chlorophyll content (Chl), photosynthesis rate (Pn), water use efficiency (WUE), electrolyte leakage (EL), leaf relative water content (RWC), and root activity (RA)

\begin{tabular}{|c|c|c|c|c|c|c|}
\hline Accession No. & PC1 & PC2 & PC3 & PC4 & PCA value & Rank \\
\hline 275,660 & 299.1 & 10.4 & 128.3 & 50.7 & 173.95 & 1 \\
\hline 598,892 & 282.5 & 16.2 & 142.3 & 84.7 & 169.99 & 2 \\
\hline 277,846 & 268.9 & -28.5 & 109.0 & 46.4 & 148.22 & 3 \\
\hline 516,605 & 242.4 & 9.7 & 156.2 & 75.7 & 148.06 & 4 \\
\hline 598,443 & 239.6 & 31.2 & 140.9 & 49.6 & 147.79 & 5 \\
\hline 610,802 & 261.1 & -33.9 & 118.7 & 75.9 & 145.94 & 6 \\
\hline 231,565 & 245.7 & -19.2 & 136.5 & 95.8 & 143.69 & 7 \\
\hline 303,026 & 194.6 & 0.9 & 169.4 & 101.1 & 123.97 & 8 \\
\hline 231,605 & 207.8 & -20.7 & 140.7 & 71.7 & 122.03 & 9 \\
\hline 182,857 & 171.5 & -3.3 & 188.3 & 116.8 & 113.60 & 10 \\
\hline 265,342 & 184.8 & -26.5 & 177.2 & 96.3 & 113.53 & 11 \\
\hline 251,224 & 170.8 & 5.3 & 180.9 & 80.8 & 111.81 & 12 \\
\hline 577,254 & 160.9 & 16.0 & 182.5 & 80.1 & 108.85 & 13 \\
\hline 231,604 & 167.9 & -13.3 & 163.7 & 90.9 & 105.78 & 14 \\
\hline 266,293 & 167.9 & -11.2 & 160.2 & 77.9 & 104.98 & 15 \\
\hline 598,839 & 129.8 & 60.5 & 187.4 & 109.5 & 104.04 & 16 \\
\hline 303,037 & 182.0 & -43.0 & 135.9 & 70.6 & 103.42 & 17 \\
\hline 418,722 & 157.7 & 2.0 & 162.7 & 67.4 & 101.77 & 18 \\
\hline 303,028 & 149.0 & -14.4 & 180.1 & 83.8 & 96.43 & 19 \\
\hline 237,187 & 146.3 & -23.3 & 167.8 & 82.4 & 92.11 & 20 \\
\hline 418,712 & 117.3 & 20.0 & 193.7 & 100.2 & 89.07 & 21 \\
\hline 371,952 & 140.9 & -41.5 & 183.4 & 109.4 & 88.79 & 22 \\
\hline 267,058 & 137.9 & -34.3 & 184.0 & 96.4 & 87.80 & 23 \\
\hline 284,826 & 132.4 & -11.1 & 172.7 & 73.1 & 87.02 & 24 \\
\hline 505,842 & 135.1 & -27.4 & 178.8 & 88.2 & 86.68 & 25 \\
\hline 600,878 & 140.6 & -49.0 & 176.7 & 103.7 & 86.10 & 26 \\
\hline 418,736 & 114.5 & 10.1 & 197.9 & 91.7 & 85.29 & 27 \\
\hline 274,637 & 137.6 & -45.1 & 179.2 & 95.3 & 84.92 & 28 \\
\hline 285,101 & 124.5 & -13.6 & 185.9 & 81.5 & 84.03 & 29 \\
\hline 578,763 & 109.4 & 19.2 & 170.4 & 81.5 & 81.49 & 30 \\
\hline 225,825 & 111.7 & -37.7 & 202.4 & 115.7 & 76.18 & 31 \\
\hline 619,003 & 98.0 & 4.3 & 199.2 & 99.5 & 76.07 & 32 \\
\hline 298,091 & 113.7 & -30.4 & 181.0 & 93.0 & 75.31 & 33 \\
\hline 418,741 & 97.6 & -0.5 & 192.6 & 108.4 & 74.99 & 34 \\
\hline 418,726 & 114.5 & -22.4 & 163.6 & 79.6 & 74.99 & 35 \\
\hline 418,723 & 98.6 & -9.3 & 200.4 & 108.4 & 74.38 & 36 \\
\hline 610,965 & 115.6 & -26.8 & 156.0 & 81.2 & 74.17 & 37 \\
\hline 267,059 & 80.9 & 19.7 & 225.7 & 112.7 & 73.38 & 38 \\
\hline 403,907 & 101.8 & -27.3 & 189.6 & 101.0 & 70.95 & 39 \\
\hline 204,880 & 90.8 & -21.1 & 207.6 & 105.2 & 68.21 & 40 \\
\hline 610,926 & 99.2 & -53.4 & 212.1 & 122.8 & 67.69 & 41 \\
\hline 418,721 & 82.3 & -6.4 & 209.3 & 104.9 & 66.85 & 42 \\
\hline
\end{tabular}


Table 2 The four major components (PC1, PC2, PC3, and PC4) and PCA ranking of each ryegrass genotypes based on turf quality (TQ), photochemical efficiency (Fv/Fm), chlorophyll content (Chl), photosynthesis rate (Pn), water use efficiency (WUE), electrolyte leakage (EL), leaf relative water content (RWC), and root activity (RA) (Continued)

\begin{tabular}{|c|c|c|c|c|c|c|}
\hline Accession No. & PC1 & PC2 & PC3 & PC4 & PCA value & Rank \\
\hline 265,351 & 88.4 & -31.8 & 187.3 & 109.6 & 63.40 & 43 \\
\hline 231,606 & 92.2 & -50.6 & 197.8 & 101.9 & 61.90 & 44 \\
\hline 303,020 & 75.8 & -15.7 & 187.1 & 94.7 & 58.97 & 45 \\
\hline 198,070 & 83.0 & -25.4 & 168.9 & 88.7 & 58.85 & 46 \\
\hline 628,717 & 76.7 & -39.8 & 207.7 & 102.3 & 56.77 & 47 \\
\hline 306,292 & 73.4 & -43.5 & 215.0 & 125.5 & 56.55 & 48 \\
\hline 290,368 & 75.4 & -55.9 & 214.5 & 121.1 & 54.73 & 49 \\
\hline 265,340 & 56.2 & -8.7 & 207.8 & 114.2 & 53.17 & 50 \\
\hline 287,855 & 42.8 & -4.7 & 242.3 & 132.5 & 51.09 & 51 \\
\hline 197,270 & 25.1 & -1.8 & 262.8 & 143.8 & 44.85 & 52 \\
\hline 502,412 & 44.7 & -17.8 & 194.8 & 102.1 & 43.29 & 53 \\
\hline 284,823 & 50.2 & -54.1 & 213.9 & 125.3 & 42.07 & 54 \\
\hline 634,205 & 39.2 & 1.7 & 158.3 & 87.2 & 40.30 & 55 \\
\hline 238,938 & 13.5 & -16.6 & 274.8 & 153.7 & 37.42 & 56 \\
\hline 321,397 & 42.2 & -29.2 & 167.4 & 101.4 & 37.39 & 57 \\
\hline 231,576 & 43.0 & -42.0 & 178.8 & 100.6 & 36.06 & 58 \\
\hline 231,595 & 24.1 & -27.5 & 215.9 & 119.6 & 33.46 & 59 \\
\hline 319,018 & 32.6 & -45.5 & 203.5 & 116.1 & 32.99 & 60 \\
\hline 420,126 & 23.3 & -50.2 & 238.8 & 140.2 & 31.79 & 61 \\
\hline 254,898 & 13.3 & -22.7 & 223.5 & 133.6 & 30.39 & 62 \\
\hline 202,451 & 11.9 & -16.4 & 205.8 & 113.2 & 27.99 & 63 \\
\hline 268,333 & 4.0 & -14.2 & 235.3 & 127.4 & 27.76 & 64 \\
\hline 598,434 & 24.7 & -41.1 & 189.3 & 102.4 & 27.61 & 65 \\
\hline 287,849 & -12.4 & -19.8 & 270.1 & 157.8 & 23.04 & 66 \\
\hline 278,773 & 17.2 & -29.3 & 158.4 & 84.2 & 22.20 & 67 \\
\hline 547,390 & -13.2 & -19.6 & 262.5 & 159.2 & 22.11 & 68 \\
\hline 231,580 & 1.3 & -23.9 & 203.9 & 118.4 & 21.13 & 69 \\
\hline 440,474 & -33.7 & 21.5 & 253.8 & 141.0 & 17.69 & 70 \\
\hline 204,085 & -26.5 & -20.6 & 284.0 & 165.4 & 17.13 & 71 \\
\hline 403,868 & -11.3 & -28.7 & 216.3 & 126.5 & 15.09 & 72 \\
\hline 598,911 & -56.4 & 11.4 & 321.2 & 179.9 & 11.99 & 73 \\
\hline 376,878 & -41.5 & -18.3 & 272.5 & 159.7 & 8.33 & 74 \\
\hline 420,128 & -33.3 & -34.1 & 259.2 & 155.7 & 8.07 & 75 \\
\hline 418,714 & -49.3 & 2.5 & 234.9 & 133.0 & 3.47 & 76 \\
\hline 418,707 & -46.7 & -41.8 & 271.7 & 163.4 & 0.96 & 77 \\
\hline 231,566 & -53.4 & -49.2 & 304.0 & 189.2 & 0.45 & 78 \\
\hline 410,155 & -38.5 & -62.2 & 267.8 & 153.9 & 0.17 & 79 \\
\hline 619,474 & -61.4 & -31.3 & 304.9 & 184.6 & -0.36 & 80 \\
\hline 577,273 & -85.5 & -3.0 & 284.4 & 170.6 & -9.95 & 81 \\
\hline 632,542 & -81.0 & -13.6 & 272.1 & 163.7 & -11.27 & 82 \\
\hline 265,344 & -82.3 & -47.0 & 283.7 & 182.6 & -16.47 & 83 \\
\hline 311,075 & -93.3 & -17.7 & 257.2 & 160.0 & -20.10 & 84 \\
\hline
\end{tabular}


Table 2 The four major components (PC1, PC2, PC3, and PC4) and PCA ranking of each ryegrass genotypes based on turf quality (TQ), photochemical efficiency (Fv/Fm), chlorophyll content (Chl), photosynthesis rate (Pn), water use efficiency (WUE), electrolyte leakage (EL), leaf relative water content (RWC), and root activity (RA) (Continued)

\begin{tabular}{|c|c|c|c|c|c|c|}
\hline Accession No. & PC1 & PC2 & PC3 & PC4 & PCA value & Rank \\
\hline 206,376 & -116.3 & 1.2 & 284.7 & 174.5 & -25.06 & 85 \\
\hline 277,848 & -109.2 & -48.9 & 316.5 & 203.2 & -26.84 & 86 \\
\hline 423,136 & -108.7 & -63.1 & 323.2 & 211.5 & -28.32 & 87 \\
\hline 610,950 & -113.6 & -13.9 & 260.8 & 153.3 & -30.17 & 88 \\
\hline 220,178 & -137.9 & -45.4 & 377.7 & 250.5 & -32.80 & 89 \\
\hline 204,879 & -123.2 & -45.0 & 317.4 & 199.0 & -33.66 & 90 \\
\hline 577,251 & -121.2 & -45.1 & 294.4 & 184.2 & -35.60 & 91 \\
\hline 577,269 & -129.7 & -55.1 & 324.2 & 209.2 & -37.87 & 92 \\
\hline 231,567 & -148.4 & -65.1 & 398.0 & 261.8 & -39.87 & 93 \\
\hline 303,027 & -174.1 & 5.5 & 350.1 & 226.2 & -45.53 & 94 \\
\hline 239,730 & -151.2 & -42.2 & 330.8 & 214.0 & -45.67 & 95 \\
\hline 317,452 & -187.5 & -1.8 & 385.2 & 239.0 & -50.24 & 96 \\
\hline 321,681 & -151.0 & -20.3 & 258.6 & 168.4 & -50.31 & 97 \\
\hline 538,976 & -290.2 & -10.9 & 399.8 & 278.6 & -102.20 & 98 \\
\hline
\end{tabular}

and evaluate contribution of each factor to the trait, which has been successfully adopted in stress tolerance evaluation in soybean (Glycine max. L.) and switchgrass (Panicum virgatum L.) [26-28]. In this study, we applied the same strategy to integrate multiple parameters to rank heat tolerance among 98 accessions of perennial ryegrass. Furthermore, through Pearson correlation analysis, we found that EL, Chl content, and RWC were closely linked to overall heat tolerance ranking based on PCA. Unlike EL and RWC, Chl content could be quickly quantified using a chlorophyll meter. Therefore, Chl content alone or combined with EL could be used as the most convenient selection criterion for a large population of perennial ryegrass germplasm for elite heat tolerance.

Among heat tolerance-related morpho- and physiological traits, loss of chlorophyll is one hallmark of heat stress damages in cool-season grass species. Our previous studies found that leaf senescence induced by heat stress was mainly due to heat accelerated $\mathrm{Chl}$ catabolism rather than attenuated $\mathrm{Chl}$ biosynthesis in one cool-season grass, creeping bentgrass (Agrostis stolonifera) and reducing Chl catabolic rate by suppressing a Chl catabolic gene $(P P H)$ in perennial ryegrass (Lolium perenne L.) delayed heat-induced leaf senescence $[25,29,30]$. Selecting for stay-green traits

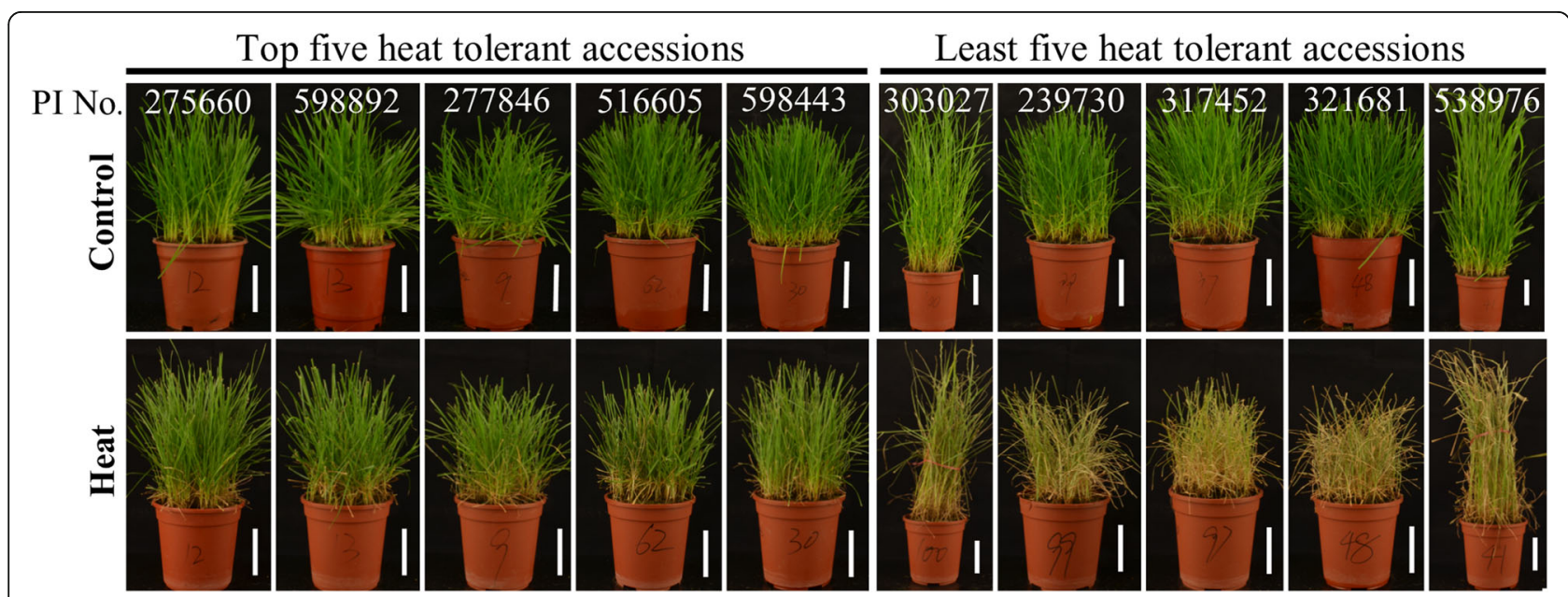

Fig. 3 Phenotype of the five most and least heat tolerant ryegrass accessions. Pictures were taken after $24 \mathrm{~d}$ of treatment. Bar in each photo represents $6.5 \mathrm{~cm}$ in length 
Table 3 Pearson correlation coefficients analysis among the value of turf quality (TQ), photochemical efficiency (Fv/Fm), chlorophyll content (Chl), photosynthesis rate (Pn), water use efficiency (WUE), electrolyte leakage (EL), leaf relative water content (RWC), root activity (RA) under heat stress conditions across 98 perennial ryegrass accessions

\begin{tabular}{|c|c|c|c|c|c|c|c|c|c|}
\hline & PCA rank value & TQ & $\mathrm{Fv} / \mathrm{Fm}$ & Chl & Pn & WUE & EL & RWC & RA \\
\hline PCA rank values & 1 & & & & & & & & \\
\hline TQ & $0.744^{* * *}$ & 1 & & & & & & & \\
\hline $\mathrm{Fv} / \mathrm{Fm}$ & $0.578^{* * *}$ & $0.750^{* * *}$ & 1 & & & & & & \\
\hline $\mathrm{Chl}$ & $0.769^{* * *}$ & $0.814^{* * *}$ & $0.671^{* * *}$ & 1 & & & & & \\
\hline $\mathrm{Pn}$ & $0.304^{* *}$ & 0.132 & 0.093 & $0.237^{*}$ & 1 & & & & \\
\hline WUE & $-0.216^{*}$ & -0.097 & 0.109 & $0.264^{* *}$ & $0.259^{* *}$ & 1 & & & \\
\hline EL & $-0.858^{* * *}$ & $-0.757^{* * *}$ & $-0.611^{* * *}$ & $-0.700^{* * *}$ & -0.163 & $0.207^{*}$ & 1 & & \\
\hline RWC & $0.764^{* * *}$ & $0.865^{* * *}$ & $0.729^{* * *}$ & $0.793^{* * *}$ & 0.099 & -0.143 & $-0.807^{* * *}$ & 1 & \\
\hline RA & $0.502^{* * *}$ & $0.563^{* * *}$ & $0.459^{* * *}$ & $0.565^{* * *}$ & 0.073 & -0.124 & $-0.411^{* * *}$ & $0.517^{* * *}$ & 1 \\
\hline
\end{tabular}

", ${ }^{* *}$ and ${ }^{* * *}$ indicate significance at $P<0.05, P<0.01$ and $P<0.001$, respectively

by controlling chlorophyll loss or leaf senescence is of great significance for improving cool-season grass species. Based on the finding that $\mathrm{Chl}$ content was associated with ryegrass heat tolerance, we checked the expression levels of CCGs in five most heat-tolerance and five heatsensitive accessions. And indeed expression levels of several CCGs were strongly correlated to the corresponding heat tolerance ranking of each ryegrass accession. Thus, we considered that $\mathrm{Chl}$ content and $\mathrm{Chl}$ catabolic genes were reliable physiological trait and marker genes for evaluation of heat tolerance in perennial ryegrass accessions.
One recent report by Shin et al. (2020) showed that the natural variation within the promoter region of a Chl catabolic gene, OsSGR, was a predominant genetic factor for delayed leaf senescence in rice, and introgression of the promoter region of OsSGR from Japonicatype rice to Indica-type rice lead to delayed leaf senescence rate and up to $12.7 \%$ increased grain yield in the Indica-type rice [31]. The study by Shen et al. (2020) showed the potential of making use of the natural variation of CCGs [31]. Findings in this study showed that there are rich natural variations of these CCGs in terms of their responses to heat tolerance, and CCGs could

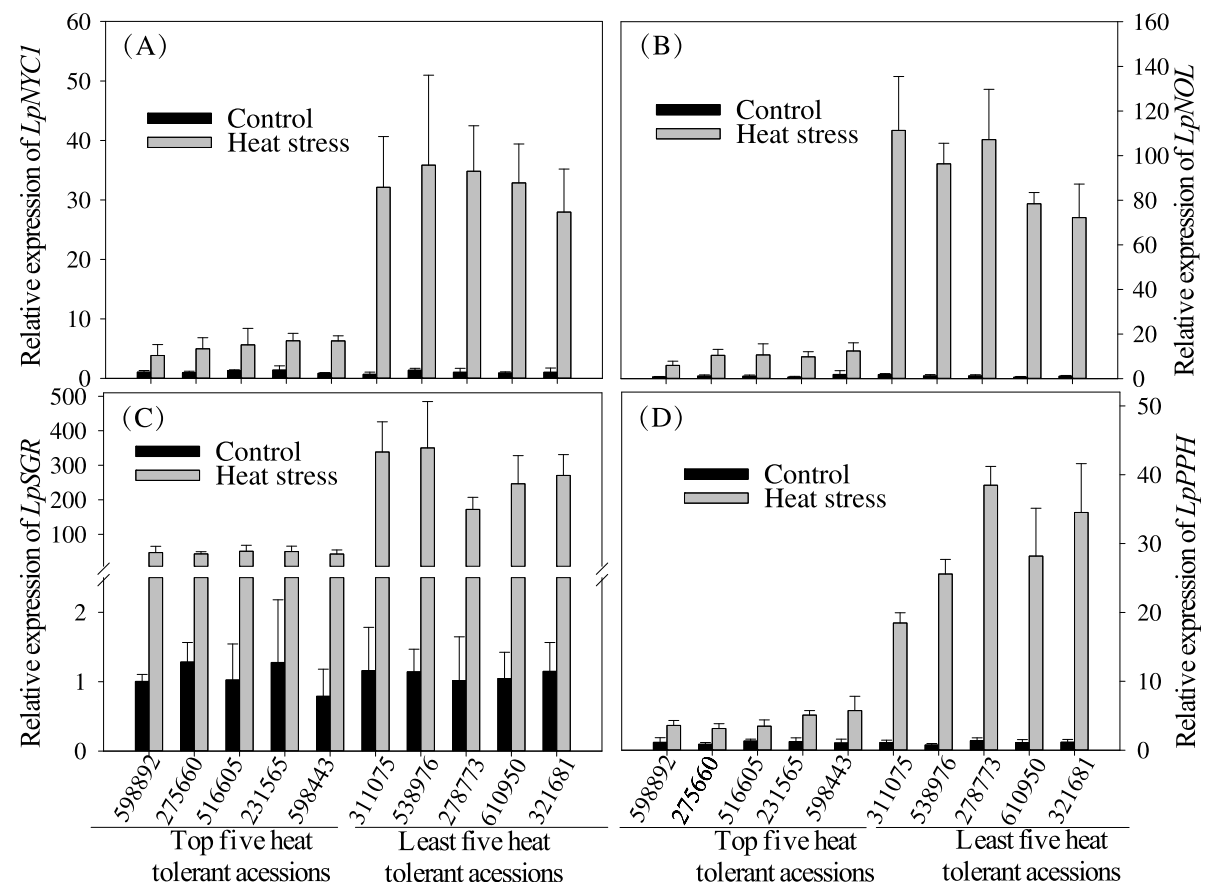

Fig. 4 Relative expression levels of four CCGs of the five most and least heat-tolerant ryegrass accessions. Relative expression levels of $L p N Y C 1$ (a), $\operatorname{LPNOL}(\mathbf{b}), \operatorname{LPSGR}(\mathbf{c})$, and LPPPH (D). Represented data were means and standard error $(n=4)$ 


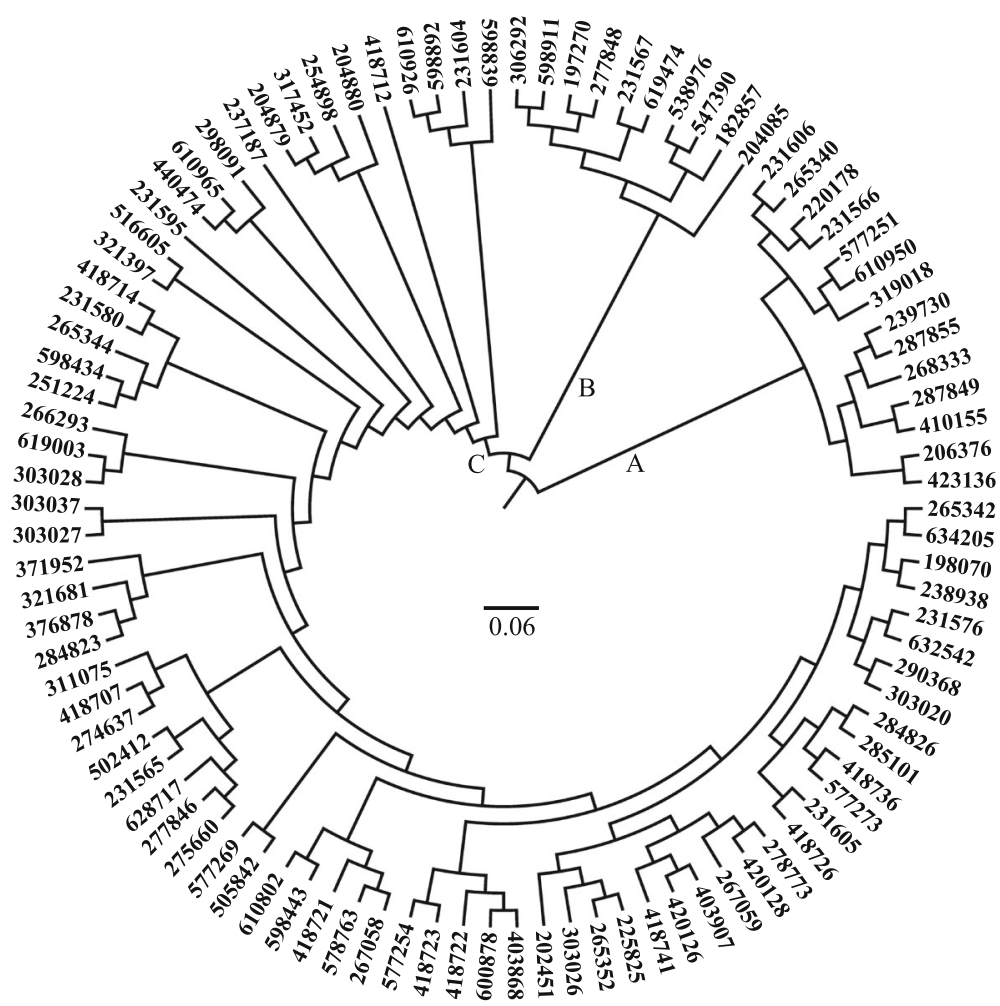

Fig. 5 Neighbour-joining tree of 98 perennial ryegrass accessions based on SSR markers

also be used as potential target genes and/or markers for genetic improvement of ryegrass through gene editing or maker-assisted breeding.

Barre et al. (2017) classified 213 perennial ryegrass accessions into three clusters according to their vegetative and reproductive investment traits (e.g. leaf growth parameters, tillering parameters, heading data and reproductive investment) [32]. In this study, the 98 accessions of perennial ryegrass were classified into three clusters according to clustering analysis using 66 pairs of SSR markers that have been used to identify alleles contributing to plant tolerance to salt, drought, submergence, and winter stress, as well as spring re-growth [16, 18, 19]. Physiological traits positively correlated to heat tolerance, including Chl content, WUE, and RA had significantly greater levels in accessions in cluster $C$ than those in cluster A and B based on SSR marker classification, suggesting that accessions in cluster $C$ were more heat tolerant than those in cluster $\mathrm{A}$ and $\mathrm{B}$, and variations in heat tolerance were related to their genetic structure in the population of perennial ryegrass examined in this study. It is also interesting to note that there is little evidence that these genetic clusters were related to their geographic location. Such a result could be interpreted by human activities' disturbance in the dispersion and distribution of perennial ryegrass.

SSR markers linked with important agronomic traits, e.g. crown rust resistance [15], submergence [18], and heading date [33] in perennial ryegrass have been identified. However, no genic SSR markers that are associated with heat tolerance in perennial ryegrass have been reported so far. In the present study, twenty-nine SSRs linked to heat tolerance-related traits were detected in perennial ryegrass. Two markers LPSSRH01A07 and

Table 4 The average value of turf quality (TQ), photochemical efficiency (Fv/Fm), chlorophyll content (Chl, mg/g DW), photosynthesis rate $\left(\mathrm{Pn}, \mu \mathrm{mol} \mathrm{CO}_{2} / \mathrm{m}^{2} / \mathrm{s}\right)$, water use efficiency $\left(\mathrm{WUE}, \mu \mathrm{mol} \mathrm{CO}_{2} / \mathrm{mmol} \mathrm{H}_{2} \mathrm{O}\right.$ ), electrolyte leakage (EL, \%), leaf relative water content (RWC, \%), root activity (RA, $\mathrm{mg} / \mathrm{g} \cdot \mathrm{h})$, and PCA ranking value of perennial ryegrass accessions in three phylogenetic clusters under heat stress condition

\begin{tabular}{|c|c|c|c|c|c|c|c|c|c|}
\hline cluster & $\mathrm{TQ}$ & $\mathrm{Fv} / \mathrm{Fm}$ & Chl & $P n$ & WUE & EL & RWC & $\mathrm{RA}$ & PCA \\
\hline $\bar{A}$ & 4.41 & 0.65 & $6.11 b$ & 3.76 & $0.67 b$ & $62.21 a$ & $57.91 b$ & $219.50 \mathrm{~b}$ & $2.65 b$ \\
\hline B & 4.97 & 0.64 & 7.23ab & 3.83 & $0.65 b$ & $65.17 a$ & 60.440ab & $223.91 b$ & $7.89 b$ \\
\hline C & 5.05 & 0.65 & $7.72 a$ & 3.77 & $0.77 a$ & 49.60b & $63.44 a$ & 234.71a & $61.67 a$ \\
\hline
\end{tabular}




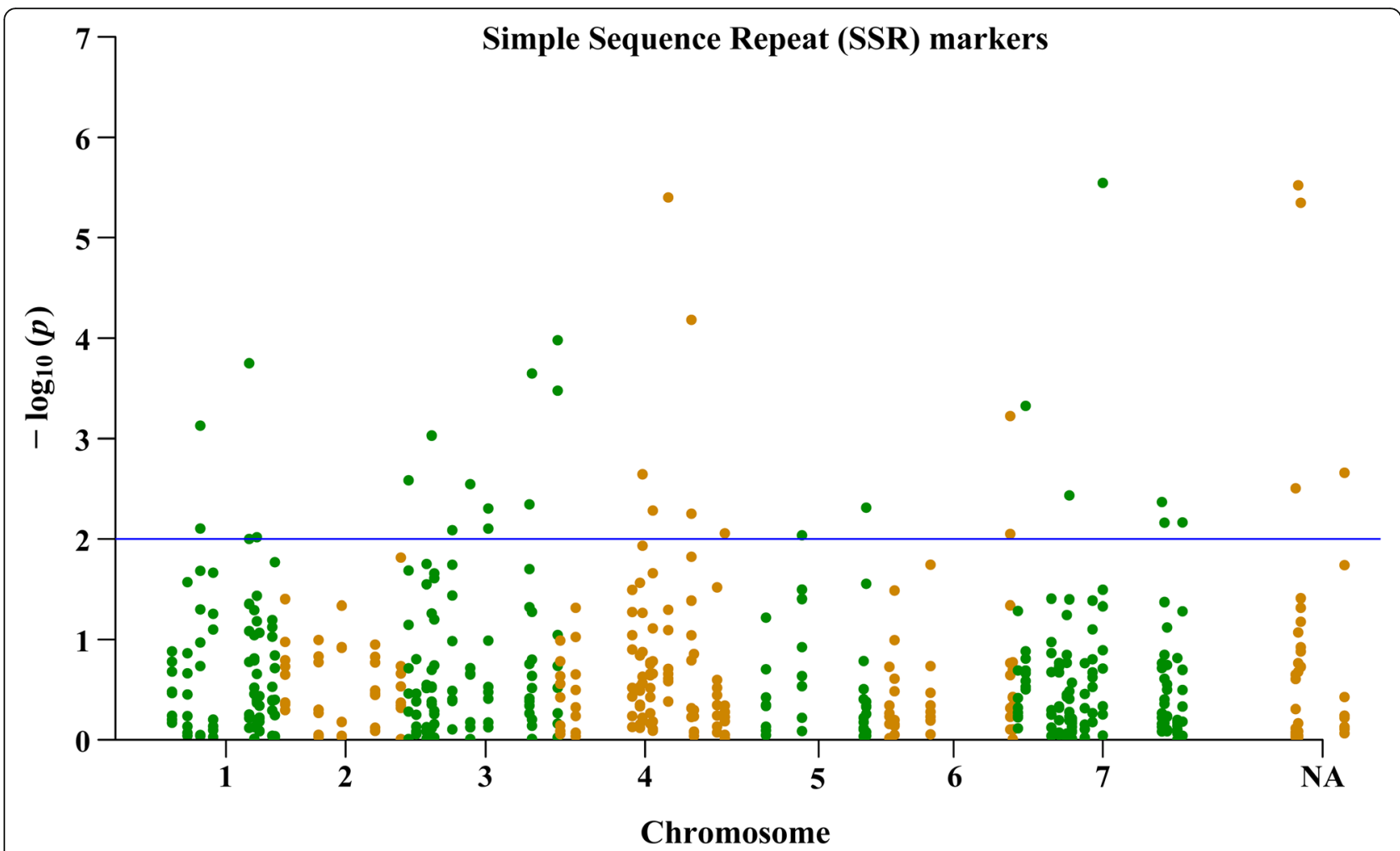

Fig. 6 Manhattan plots of the general linear model (GLM) for association analysis between SSR markers and each physiological trait. The $-\log _{10}(P-$ values) from each SRR markers are plotted against eight heat tolerance-related traits, including TQ, Fv/Fm, Chl content, Pn, WUE, RWC, RA, and EL. NA, not known

LPSSRH02C11, both located on chromosome 4, which were reported to be associated with relative growth rate under submergence stress [18], were correlated with WUE and RA in this study, suggesting a QTL in chromosome 4 could also affect heat tolerance. It is interesting to find that three markers M4213, B3B7, and PR37, located on chromosome 1 with $6 \mathrm{cM}$ apart, were linked to WUE. In addition, Lp165, DLF008, and B3C10 located on chromosome 7 with $12 \mathrm{cM}$ apart, were associated with $\mathrm{Fv} / \mathrm{Fm}$. Thus, it is most likely that a QTL for WUE and Fv/Fm located at chromosome 1 and 7, respectively. The results indicate that at least three candidate QTLs located in these chromosome positions play an important role in heat tolerance of perennial ryegrass.

\section{Conclusion}

In summary, heat tolerance varied widely among 98 accessions of perennial ryegrass examined in this study. The most and least heat-tolerant accessions were identified, and accessions in cluster $\mathrm{C}$ were relatively more heat tolerant than those in cluster A and B. EL, Chl content and CCGs were reliable physiological traits and marker genes for heat stress tolerance assessment in perennial ryegrass. Furthermore, SSR markers associated with Chl content, $\mathrm{Fv} / \mathrm{Fm}, \mathrm{Pn}, \mathrm{WUE}, \mathrm{EL}$, and RA were also identified. The result highlighted the importance of cell membrane stability and Chl catabolism in heat tolerance of cool-season grasses. Such knowledge is of significance for heat-tolerance breeding of perennial ryegrass and for further studies on heat tolerance mechanisms in perennial ryegrass as well as in other cool-season grass species.

\section{Methods}

Plant materials and growth conditions

A collection of 98 perennial ryegrass accessions was obtained from United States Department of Agriculture's National Plant Germplasm System (USDA-GRIN), including 37 wild, 33 cultivated, and 28 with uncertain pedigree accessions (Table 6). A single seed of each germplasm was sown in plastic pots $(13 \mathrm{~cm}$ diameter and $13 \mathrm{~cm}$ height) filled with fritted clay and maintained in a greenhouse at Nanjing Agricultural University, Jiang $\mathrm{Su}$, China. Each accession was propagated using tillers to generate stock plants. In this experiment, tillers from stock plants of each accession were transplanted into eight pots (10 tillers in each pot) and maintained in a growth chamber controlled at $25 / 20^{\circ} \mathrm{C}$ (day/night temperature), $70 \%$ relative humidity, a photoperiod of $16 \mathrm{~h}$, and photosynthetic active radiation of $750 \mu \mathrm{mol}$ 
Table 5 Association of SSR markers with the heat stress index of Fv/Fm, Chl content, Pn, WUE, RA, and EL

\begin{tabular}{|c|c|c|c|c|c|}
\hline Trait & Locus & Chromosome No. & Position (cM) & $P$ value & $R^{2}$ \\
\hline $\mathrm{Fv} / \mathrm{Fm}$ & LP165 & 7 & 66 & $2.85 \mathrm{E}-06$ & 0.67 \\
\hline $\mathrm{Fv} / \mathrm{Fm}$ & rv0941 & 4 & 20.3 & $6.57 \mathrm{E}-05$ & 0.47 \\
\hline $\mathrm{Fv} / \mathrm{Fm}$ & DLF008 & 7 & 77 & 4.74E-04 & 0.49 \\
\hline $\mathrm{Fv} / \mathrm{Fm}$ & $\mathrm{B} 3 \mathrm{C} 10$ & 7 & 80 & $3.68 \mathrm{E}-03$ & 0.29 \\
\hline $\mathrm{Fv} / \mathrm{Fm}$ & B3B8 & 3 & 70 & $8.18 \mathrm{E}-03$ & 0.48 \\
\hline $\mathrm{Fv} / \mathrm{Fm}$ & B5E1 & 5 & NA & $9.20 \mathrm{E}-03$ & 0.19 \\
\hline Chl & M144 & 4 & 56 & $5.21 \mathrm{E}-03$ & 0.52 \\
\hline Chl & rv0941 & 4 & 20.3 & $5.60 \mathrm{E}-03$ & 0.37 \\
\hline Pn & rv0985-1 & 6 & 51.7 & $8.92 \mathrm{E}-03$ & 0.64 \\
\hline WUE & PRG & 4 & 119 & $3.98 \mathrm{E}-06$ & 0.53 \\
\hline WUE & PR10 & NA & NA & 4.50E-06 & 0.47 \\
\hline WUE & M4213 & 1 & 46 & $1.78 \mathrm{E}-04$ & 0.44 \\
\hline WUE & $25 c a 1$ & 3 & 91.1 & $2.25 \mathrm{E}-04$ & 0.56 \\
\hline WUE & LPSSRH01A07 & 3 & NA & 3.34E-04 & 0.33 \\
\hline WUE & rv0985-1 & 6 & 51.7 & 5.99E-04 & 0.70 \\
\hline WUE & rv0005 & 7 & 0 & $4.28 \mathrm{E}-03$ & 0.75 \\
\hline WUE & rv1133 & 3 & 27.8 & 4.52E-03 & 0.17 \\
\hline WUE & LPSSRH02C11 & 3 & NA & 4.97E-03 & 0.37 \\
\hline WUE & rv0663 & 7 & 6.7 & $6.88 \mathrm{E}-03$ & 0.31 \\
\hline WUE & B3B7 & 1 & 49 & 7.87E-03 & 0.29 \\
\hline WUE & LpHCA16B2 & 4 & 0 & 8.79E-03 & 0.48 \\
\hline WUE & PR37 & 1 & 52 & $9.62 \mathrm{E}-03$ & 0.48 \\
\hline RA & M844 & NA & NA & $3.01 \mathrm{E}-06$ & 0.60 \\
\hline RA & LPSSRH01A07 & 3 & NA & 1.05E-04 & 0.35 \\
\hline RA & B3B7 & 1 & 49 & 7.47E-04 & 0.35 \\
\hline RA & $\mathrm{B} 1 \mathrm{~A} 10$ & 3 & 74 & 9.35E-04 & 0.63 \\
\hline RA & LpSSR100 & 3 & 62 & $2.60 \mathrm{E}-03$ & 0.21 \\
\hline RA & LP194 & NA & NA & $3.12 \mathrm{E}-03$ & 0.47 \\
\hline RA & rv0757 & 5 & 77.7 & 4.87E-03 & 0.72 \\
\hline RA & LPSSRH02C11 & 3 & NA & 7.88E-03 & 0.36 \\
\hline EL & LM15 & NA & NA & $2.18 \mathrm{E}-03$ & 0.32 \\
\hline EL & LPSSRH01H06 & 4 & 43 & $2.26 \mathrm{E}-03$ & 0.44 \\
\hline EL & rye012 & 4 & 53 & 2.83E-03 & 0.12 \\
\hline EL & LpHCA17C6 & 5 & NA & $6.84 \mathrm{E}-03$ & 0.74 \\
\hline
\end{tabular}

NA, not known

$\mathrm{m}^{-2} \mathrm{~s}^{-1}$ for $60 \mathrm{~d}$. Plants were maintained at a height of $12 \mathrm{~cm}$ by weekly mowing and fertilized weekly with halfstrength Hoagland's nutrient solution [34].

\section{Temperature treatments}

Plants in four pots (four replicates) for each accession were exposed to normal growth temperature of $25 / 20^{\circ} \mathrm{C}$ (day/night) or heat stress at $35 / 30^{\circ} \mathrm{C}$ (day/night) in growth chambers. Each temperature treatment was repeated in two growth chambers. Plants were subjected to those temperature conditions for $24 \mathrm{~d}$. The plants received regular water and fertilization during the treatment period.

\section{Phenotypic and physiological measurements}

For leaf width (LW) analysis, 10 mature leaves of each accession were measured using a digital caliper. Maximum plant height $(\mathrm{PH})$ was measured manually as the length from the base to the top of each plant. TQ was visually rated using a 1-9 scale based on plant color, 
Table 6 Accession number (PI No.), origin, status, and genetic clusters of 98 perennial ryegrass accessions

\begin{tabular}{|c|c|c|c|c|c|c|c|}
\hline Accession No. & Origin & Status $^{\mathrm{a}}$ & Cluster & Accession No. & Origin & Status $^{\mathrm{a}}$ & Cluster \\
\hline 287,855 & Spain & U & $A$ & 284,823 & Australia & $U$ & C \\
\hline 231,606 & Portugal & U & A & 231,604 & Portugal & U & C \\
\hline 610,950 & Morocco & W & A & 516,605 & Yugoslavia & $C D$ & C \\
\hline 220,178 & Afghanistan & W & A & 371,952 & Bulgaria & $U$ & C \\
\hline 265,340 & Portugal & U & A & 440,474 & Former USSR & W & C \\
\hline 319,018 & Spain & U & A & 265,351 & Chile & U & C \\
\hline 410,155 & South Africa & W & A & 231,576 & Algeria & U & C \\
\hline 577,251 & Morocco & W & A & 418,726 & France & W & C \\
\hline 231,566 & Libya & U & A & 403,868 & Canada & C & C \\
\hline 287,849 & Spain & $U$ & A & 231,580 & Algeria & $U$ & C \\
\hline 239,730 & Egypt & $U$ & A & 634,205 & USA & C & C \\
\hline 206,376 & Cyprus & U & A & 198,070 & Sweden & $C D$ & $\mathrm{C}$ \\
\hline 268,333 & Former USSR & W & A & 321,681 & France & C & C \\
\hline 423,136 & Spain & W & A & 266,293 & Netherlands & $C D$ & C \\
\hline 182,857 & Czech Republic & U & $\mathrm{B}$ & 578,763 & USA & C & C \\
\hline 538,976 & Russia & C & B & 321,397 & Czech Republic & $U$ & C \\
\hline 197,270 & Finland & $C D$ & B & 303,020 & Sweden & C & C \\
\hline 547,390 & Iran & W & B & 231,595 & Morocco & $U$ & C \\
\hline 204,085 & Cyprus & U & B & 418,721 & Belgium & W & C \\
\hline 619,474 & Romania & $C D$ & B & 418,722 & Luxembourg & W & C \\
\hline 306,292 & Bolivia & U & B & 418,741 & France & W & C \\
\hline 277,848 & Cyprus & $U$ & B & 619,003 & Norway & W & C \\
\hline 231,567 & Libya & U & B & 251,224 & Yugoslavia & W & C \\
\hline 598,911 & Tunisia & W & B & 628,717 & Bulgaria & W & $\mathrm{C}$ \\
\hline 598,839 & Morocco & W & C & 290,368 & Hungary & U & C \\
\hline 418,712 & Yugoslavia & U & C & 376,878 & New Zealand & C & C \\
\hline 277,846 & Yugoslavia & U & C & 303,037 & Sweden & C & C \\
\hline 610,802 & Norway & W & C & 420,126 & Japan & U & C \\
\hline 231,565 & Libya & U & C & 204,880 & Turkey & W & C \\
\hline 225,825 & Denmark & U & C & 265,344 & Ireland & C & C \\
\hline 204,879 & Turkey & W & C & 237,187 & Netherlands & $C D$ & C \\
\hline 265,342 & Ireland & C & C & 577,254 & Luxembourg & W & C \\
\hline 303,026 & France & C & C & 274,637 & Poland & $U$ & C \\
\hline 275,660 & Australia & $C D$ & C & 298,091 & Hungary & W & C \\
\hline 418,723 & Luxembourg & W & C & 285,101 & Australia & C & C \\
\hline 577,273 & Turkey & W & C & 505,842 & Former USSR & $C D$ & $\mathrm{C}$ \\
\hline 577,269 & Norway & W & C & 632,542 & Hungary & C & C \\
\hline 238,938 & New Zealand & U & C & 610,965 & Italy & W & C \\
\hline 267,059 & Poland & U & C & 202,451 & Argentina & W & C \\
\hline 303,027 & Denmark & C & C & 231,605 & France & C & C \\
\hline 317,452 & Afghanistan & W & C & 284,826 & Australia & $U$ & C \\
\hline 403,907 & Canada & C & C & 502,412 & Russia & W & C \\
\hline 278,773 & Canada & C & C & 418,714 & Italy & W & C \\
\hline 254,898 & Iraq & W & C & 598,434 & Italy & W & C \\
\hline
\end{tabular}


Table 6 Accession number (PI No.), origin, status, and genetic clusters of 98 perennial ryegrass accessions (Continued)

\begin{tabular}{|c|c|c|c|c|c|c|c|}
\hline Accession No. & Origin & Status $^{\mathrm{a}}$ & Cluster & Accession No. & Origin & Status $^{a}$ & Cluster \\
\hline 267,058 & Poland & $U$ & C & 610,926 & Tunisia & W & $C$ \\
\hline 418,736 & Switzerland & W & C & 420,128 & Japan & $C$ & $C$ \\
\hline 598,443 & Switzerland & W & C & 418,707 & Romania & W & $C$ \\
\hline 600,878 & USA & $C$ & C & 598,892 & Tunisia & W & $C$ \\
\hline 303,028 & Denmark & C & C & 311,075 & Romania & $U$ & $C$ \\
\hline
\end{tabular}

Status $^{\text {a }}$ : Improvement status obtained from USDA germplasm bank

$U$ uncertain, $W$ wild, $C$ cultivar, $C D$ cultivated

shoot density and uniformity to assess the overall plant health and vigor (1 represents brown and dead plant, and 9 represents the best plant in all these quality components) [35]. Fv/Fm was determined using a fluorescence meter (Dynamax, Houston, TX, USA), described previously by Oxborough and Baker (1997) [36]. Chl content was measured according to the method by Arnon (1949) [37]. For RWC quantification, about $0.1 \mathrm{~g}$ fresh leaves were detached and immediately weighed as the fresh weight (FW), then soaked in distilled water and maintained at $4{ }^{\circ} \mathrm{C}$ in the dark for $24 \mathrm{~h}$ and weighted as turgid weight (TW). Leaf samples were then placed in an oven at $80^{\circ} \mathrm{C}$ for $72 \mathrm{~h}$ prior to being weighted for dry weight (DW). The RWC was calculated as formula: (FW$\mathrm{DW}) /(\mathrm{TW}-\mathrm{DW}) \times 100 \%$ [38]. Pn and WUE were measured according to the method described by Burgess and Huang (2014) using a portable photosynthesis system (Li-COR6400, LI-COR Inc., Lincoln, NE, USA) [39]. For quantification of EL, approximately $0.2 \mathrm{~g}$ of leaves were collected, rinsed three times with distilled water, and then placed into a $50 \mathrm{ml}$ tubes containing $30 \mathrm{ml}$ distilled water. Initial conductivity $(\mathrm{Ci})$ was quantified using a conductivity meter (YSI Model 32, Yellow Spring, OH) after shaking for $24 \mathrm{~h}$. The samples were then autoclaved for $30 \mathrm{~min}$. The maximum conductivity (Cmax) was measured after the tubes were cooled to room temperature. The relative EL was calculated as $(\mathrm{Ci} / \mathrm{Cmax}) \times 100$.

RA was measured using 2,3,5-triphenyl tetrazolium chloride (TTC) reduction method [40]. The TTC reduction assay was performed following the method of Steponkus and Lanphear (1967) with minor modifications [41]. In brief, approximately $0.5 \mathrm{~g}$ root tips $(0-$ $50 \mathrm{~mm}$ ) were excised and washed three times with distilled water and transferred to $10 \mathrm{ml}$ TTC solution (0.4\% TTC in $0.1 \mathrm{M}$ sodium phosphate buffer, $\mathrm{pH}$ 7.0). After $3 \mathrm{~h}$ incubation at $37^{\circ} \mathrm{C}$, TTC solution was removed and root segments were washed with distilled water. The roots were cut into $1 \mathrm{~cm}$ segments and incubated overnight at room temperature in 10 $\mathrm{ml}$ of $95 \%$ ethanol. The reduction of TTC was expressed as the absorbance of the extraction solution at $485 \mathrm{~nm}$.

\section{Ranking of overall heat tolerance}

Principal component analysis (PCA) was used to rank heat tolerance of 98 accession, following the method used in ranking of drought and salinity tolerance for different grass genotypes as described in Liu et al. (2015) [27] and Tang et al. (2013) [19]. PCA ranking value for each accession was calculated using the formula: PCA rank value $=\sum_{j=1}^{n}[P C j$ $\times$ contribution of $P C j(\%)] j=1,2,3, \ldots, n$ [42]. In this formula, 'PCj' represents the value of principal component $j$ and 'contribution of $\mathrm{PCj}$ (\%)' represents the variance in response to stress treatment that principal component $j$ could explain. When the total contribution of first several PCs was higher than 85\%, these PCs were selected for PCA rank calculation [43]. Relative heat tolerance of 98 perennial ryegrass accessions was subsequently ranked according to their PCA ranking values.

The absolute value of each physiological value across different accessions cannot faithfully represent the degree of their heat tolerance. For example, an accession with low Chl content after heat stress cannot tell whether this low content was due to the stress or due to other factors (e.g. it might be low even without heat stress). Therefore, we used a relative value, Heat stress index (HSI), for the stresstolerance evaluation [26]: HSI = (value of parameter under heat stress condition) / (value of parameter under control condition) $\times 100$.

\section{Genetic diversity and association analysis}

A total of 66 pairs of publicly available SSR primers of nuclear DNA distributed on seven chromosomes (Supplementary materials 3) were used to genotype the 98 perennial ryegrass accessions [19]. PCR reaction was performed in a $10 \mu \mathrm{l}$ reaction volume with 60 ng DNA, 1.0 unit of Taq DNA Polymerase, $1 \times$ PCR buffer, $0.2 \mathrm{mM}$ dNTP mix, $2.5 \mathrm{mM} \mathrm{MgCl}_{2}$, 
$0.05 \mu \mathrm{M}$ forward tailed primer, $0.05 \mu \mathrm{M}$ fluorescent labeled M13 primer, and $0.1 \mu \mathrm{M}$ reverse primer. All PCR reactions were carried out in a Bio-Rad thermocycler (Bio-Rad Inc., Hercules, CA, USA) using a touch-down program described by $\mathrm{Yu}$ et al. (2013) [16]. PCR products were separated in an ABI 3730 DNA Sequencer (Applied Biosystem, Inc., Foster City, CA, USA). Alleles were identified by GeneMarker 1.6 software (SoftGenetics, LLC, State College, PA, USA). The allelic bands with at least $2 \mathrm{bp}$ differences were considered as polymorphic among accessions. All confirmed polymorphic alleles were used for cluster analysis.

Nei's genetic distance among accessions was estimated by the "Phylogeny" function of PowerMarker software version 3.25 based on the SSR marker data [44]. The Nei's genetic distance was then used for cluster analysis and generation of Neighbour Joining $(\mathrm{N}-\mathrm{J})$ dendrogram by FigTree version 1.4.2 (http://tree.bio.ed.ac.uk/software/figtree/) [45]. Association analysis of SSR markers with heat tolerance traits was conducted using TASSEL 5.0 software along with the general liner model (GLM) procedure [46]. $P \leq 0.01$ was used to identify significant associations.

\section{Gene expression analysis}

The Qiagen RNA Extraction Kit (Qiagen, Valencia, CA, USA) was used to extract total RNA form perennial ryegrass leaves following the manufacturer's instructions. The first-strand cDNA was synthesized using the High Capacity cDNA Reverse Transcription Kit (Applied Biosystems, Grand Island, NY, USA). The qRT-PCR reaction was performed using the Roche LightCycler 480 II RealTime PCR System (Roche Molecular Systems, Inc., Branchburg, NJ, USA). All PCR reactions were performed in a $20 \mu \mathrm{l}$ reaction volume with four biological replicates. Primers used for qRT-PCR analysis were listed in supplementary Table 3 and LpeIHF4A was used as a reference gene [47].

\section{Data analysis}

Data from all samples were subjected to analysis of variance (ANOVA) using SAS 9.3 software (SAS Institute Inc., Cary, NC, USA) as shown in Table 1. Treatment means were separated using Fisher's protected LSD test at a 0.05 probability level as shown in Table 4 and Fig. 4. Pearson correlation analysis between physiological parameters was performed using the Bivariate Correlations program in software SPSS for Windows (Version 12, SPSS Inc., Chicago, IL) as shown in Table 3. Heatmap (Fig. 1) and principal component analysis (PCA) (Fig. 2) of the morphological and physiological parameters were performed using $\mathrm{R}$ statistical software (R3.5.2 by $\mathrm{R}$ Development Core Team).

\section{Supplementary information}

Supplementary information accompanies this paper at https://doi.org/10. 1186/s12870-020-02695-8.

Additional file 1: Table S1. Eigenvectors and percentage of accumulated contribution ratios of each principal component. Table S2. Principle component analysis of eight physiological traits across 98 perennial ryegrass accessions using heat stress index (HSI) after 24 days of treatment. Table S3. Primers used for gene expression analysis.

Additional file 2: Supplementary materials 1. Values of all physiological traits before and after heat tolerance in 98 ryegrass accessions.

Additional file 3: Supplementary materials 2. Major allele frequency, polymorphic bands, polymorphism information content, and gene diversity index of 66 pairs of SSR used for genetic diversity analysis in 98 ryegrass accessions.

Additional file 4: Supplementary materials 3. Linkage group, physical distance, and primer sequences of 66 SSRs used in this study.

\section{Abbreviations}

Chl: Chlorophyll; CCGs: Chl catabolic genes; TQ: Turf quality; Fv/ Fm: Photochemical efficiency; RWC: Leaf relative water content; EL: Electrolyte leakage; Pn: Photosynthetic rate; WUE: Water use efficiency; RA: Root activity; LW: Leaf width; PH: Maximum plant height; PCA: Principal component analysis; HIS: Heat stress index; SSR: Simple sequence repeat

\section{Acknowledgements}

We thank United States Department of Agriculture's National Plant Germplasm System (USDA-GRIN) for kindly providing the ryegrass accessions.

\section{Authors' contributions}

$J Z, B X$, and $B H$ design of this study. $J Z, \mathrm{HL}^{1}, \mathrm{HL}^{4}, \mathrm{ZZ}$ and $\mathrm{ZX}$ performed the experiment and analyzed the data. $J Z$ and $B X$ wrote the manuscript. $Y J$ and $\mathrm{BH}$ analyzed the data and revised the manuscript. All authors have read and approved the manuscript.

\section{Funding}

The design of the study was supported by the grant of Natural Science Foundation of Jiangsu Province (grant no. BK20180546). Data collection, analysis, and interpretation was supported by the grant of National Natural Science Foundation of China [grant Nos. 31802117 and 31772659 ].

\section{Availability of data and materials}

The data sets and materials supporting the findings of this article are presented within the manuscript and its supplementary information files.

Ethics approval and consent to participate

Not applicable.

Consent for publication

Not applicable.

\section{Competing interests}

The authors declare that they have no conflict of interest.

\section{Author details}

${ }^{1}$ College of Agro-grassland Science, Nanjing Agricultural University, Nanjing 210095, P.R. China. ${ }^{2}$ Department of Agronomy, Purdue University, West Lafayette, IN 47907, USA. ${ }^{3}$ College of Agronomy, Hebei Agricultural University/State Key Laboratory of North China Crop Improvement and Regulation/Key Laboratory of Crop Growth Regulation of Hebei Province, Baoding 071001, Hebei, China. ${ }^{4}$ Shanghai Biotechnology Corporation, Zhangjiang Hi-tech Park, Shanghai 201203, P.R. China. ${ }^{5}$ Department of Plant Biology and Pathology, Rutgers, the State University of New Jersey, New Brunswick, NJ 08901, USA. 
Received: 21 June 2020 Accepted: 12 October 2020

Published online: 16 November 2020

\section{References}

1. Xu Y, Wang J, Bonos SA, Meyer WA, Huang B. Candidate genes and molecular markers correlated to physiological traits for heat tolerance in fine fescue cultivars. Int J Mol Sci. 2018;19.

2. Jespersen D, Merewitz E, Xu Y, Honig J, Bonos S, Meyer W, Huang B. Quantitative trait loci associated with physiological traits for heat tolerance in creeping bentgrass. Crop Sci. 2016;56:1314-29.

3. Krans JV, Philley HW, Goatley JM, Maddox VL. Registration of twelve creeping bentgrass germplasms selected in Mississippi. Crop Sci. 2000;40:582.

4. Minner DD, Dernoeden PH, Wehner DJ, Mclntosh MS. Heat tolerance screening of field-grown cultivars of Kentucky bluegrass and perennial ryegrass. Agron J. 1983:75:772-5.

5. Cao X, Mondal S, Cheng D, Wang C, Liu A, Song J, Li H, Zhao Z, Liu J. Evaluation of agronomic and physiological traits associated with high temperature stress tolerance in the winter wheat cultivars. Acta Physiol Plant. 2015;37:90

6. Varshney RK, Baum M, Guo P, Grando S, Ceccarelli S, Graner A. Features of SNP and SSR diversity in a set of ICARDA barley germplasm collection. Mol Breed. 2010;26:229-42.

7. Li C, Song L, Zhu Y, Zhai Y, Wang Q. Genetic diversity assessment of upland cotton variety resources in China based on phenotype traits and molecular markers. Crop Sci. 2017;57:290-301.

8. Ober ES, Bloa ML, Clark CJA, Royal A, Jaggard KW, Pidgeon JD. Evaluation of physiological traits as indirect selection criteria for drought tolerance in sugar beet. Field Crop Res. 2005;91:231-49.

9. Larkindale J, Hall JD, Knight MR, Vierlin E. Heat stress phenotypes of Arabidopsis mutants implicate multiple signaling pathways in the acquisition of thermotolerance. Plant Physiol. 2005;138:882-97.

10. Shah F, Huang J, Cui K, Nie T, Shah T, Chen C, Wang K. Impact of hightemperature stress on rice plant and its traits related to tolerance. J Agric Sci. 2011;149:545-56

11. Zhang J, Shi Y, Zhang X, Du H, Xu B, Huang B. Melatonin suppression of heat-induced leaf senescence involves changes in abscisic acid and cytokinin biosynthesis and signaling pathways in perennial ryegrass (Lolium perenne L.). Environ Exp Bot. 2017;138:36-45.

12. Annicchiaric P, Pecetti L. Yield vs. morphophysiological trait-based criteria for selection of durum wheat in a semi-arid Mediterranean region (northern Syria). Field Crop Res. 1998;59:163-73.

13. Munns R, Husain S, Rivelli AR, James RA, Condon AG, Lindsay MP, Lagudah ES, Schachtman DP, Hare RA. Avenues for increasing salt tolerance of crops, and the role of physiologically based selection traits. Plant Soil. 2002;247:93-105.

14. Mondal S, Singh R, Huerta-Espino J, Kehel Z, Autrique E. Characterization of heat- and drought-stress tolerance in high-yielding spring wheat. Crop Sci. 2015:55:1552.

15. Dumsday JL, Smith KF, Forster JW, Jones ES. SSR-based genetic linkage analysis of resistance to crown rust (Puccinia coronata f. sp. Iolii) in perennial ryegrass (Lolium perenne). Plant Pathol. 2003:52:628-37.

16. Yu X, Bai G, Liu S, Luo N, Wang Y, Richmond DS, Pijut PM, Jackson SA, Yu J, Jiang $Y$. Association of candidate genes with drought tolerance traits in diverse perennial ryegrass accessions. J Exp Bot. 2013;64:1537-51.

17. Yu X, Pijut PM, Byrne S, Asp T, Bai G, Jiang Y. Candidate gene association mapping for winter survival and spring regrowth in perennial ryegrass. Plant Sci. 2015;235:37-45.

18. Yu X, Bai G, Luo N, Chen Z, Liu S, Liu J, Warnke SE, Jiang Y. Association of simple sequence repeat (SSR) markers with submergence tolerance in diverse populations of perennial ryegrass. Plant Sci. 2011;180:391-8.

19. Tang J, Yu X, Luo N, Xiao F, Camberato JJ, Jiang Y. Natural variation of salinity response, population structure and candidate genes associated with salinity tolerance in perennial ryegrass accessions. Plant Cell Environ. 2013; 36:2021-33.

20. Altpeter F, Xu J, Ahmed S. Generation of large numbers of independently transformed fertile perennial ryegrass (Lolium perenne L.) plants of forageand turf-type cultivars. Mol Breed. 2000;6:519-28.

21. Chastain TG, King MC, Garbacik CJ, Young WC, Wysocki DJ. Irrigation frequency and seasonal timing effects on perennial ryegrass (Lolium perenne L.) seed production. Field Crop Res. 2015;180:126-34.

22. Barnabás B, Jäger K, Fehér $A$. The effect of drought and heat stress on reproductive processes in cereals. Plant Cell Environ. 2010;31:11-38.
23. Jiang $Y$, Huang B. Drought and heat stress injury to two cool-season turfgrasses in relation to antioxidant metabolism and lipid peroxidation. Crop Sci. 2001;41:436-42.

24. Kahan AR, Cheng Z, Ghazanfar B, Kahan MA, Zhu Y. Acetyl salicylic acid and 2, 4-epibrassinolide enhance root activity and improve root morphological features in tomato plants under heat stress. Acta Agric Scand Sect B Soil Plant Sci. 2014;64:304-11.

25. Zhang J, Xing J, Lu Q, Yu G, Xu B, Huang B. Transcriptional regulation of chlorophyll-catabolic genes associated with exogenous chemical effects and genotypic variations in heat-induced leaf senescence for perennial ryegrass. Environ Exp Bot. 2019;167:103858.

26. Bouslama M, Schapaugh WT. Stress tolerance in soybeans. I. Evaluation of three screening techniques for heat and drought tolerance. Crop Sci. 1984; 24:933-7.

27. Liu Y, Zhang X, Tran H, Shan L, Kim J, Childs K, Ervin EH, Frazier T, Zhao B. Assessment of drought tolerance of 49 switchgrass (Panicum virgatum) genotypes using physiological and morphological parameters. Biotechnol Biofuels. 2015;8:152.

28. Wójcik-Jagła M, Rapacz M, Tyrka M, Kościelniak J, Crissy K, Żmuda K Comparative QTL analysis of early short-time drought tolerance in polish fodder and malting spring barleys. Theor Appl Genet. 2013;126:3021-34.

29. Jespersen D, Zhang J, Huang B. Chlorophyll loss associated with heatinduced senescence in bentgrass. Plant Sci. 2016;249:1-12.

30. Zhang J, Yu G, Wen W, Ma X, Xu B, Huang B. Functional characterization and hormonal regulation of the pheophytinase gene $L P P P H$ controlling leaf senescence in perennial ryegrass. J Exp Bot. 2016;67:935-45.

31. Shin D, Lee S, Kim T, Lee J, Park, Lee J, Lee J, Cho L, Choi J, Lee W, Park J, Lee D, Ito H, Kim D, Tanaka A, Cho J, Song Y, Hwang D, Purugganan M, Jeon J, An G, Nam H. Natural variations at the Stay-Green gene promoter control lifespan and yield in rice cultivars. Nat Commun. 2020;11:2819.

32. Barre P, Ruttink T, Muylle H, Lootens PJ, Sampoux P, Rohde A, Combes D, Roldán-Ruiz I. Natural diversity in vegetative and reproductive investments of perennial ryegrass is shaped by the climate at the place of origin. Grass Forage Sci. 2017:73:13.

33. King J, Thorogood D, Edwards KJ, Armsterad L, Roberts K, Skot Z, Hanley KIP. Development of a genomic microsatellite library in perennial ryegrass (Lolium perenne) and its use in trait mapping. Ann Bot. 2008;101:845-53.

34. Hoagland DR, Arnon DI. The water-culture method for growing plants without soil. Cir Calif Agric Exp Stn. 1950;347:357-9.

35. Turgeon AJ. Turfgrass Management. Prentice-Hall Inc; 1991.

36. Oxborough K, Baker NR. Resolving chlorophyll a fluorescence images of photosynthetic efficiency into photochemical and non-photochemical components-calculation of qP and Fv-/Fm-; without measuring Fo. Photosynth Res. 1997;54:135-42.

37. Arnon Dl. Copper enzymes in isolated chloroplasts, polyphenoloxidase in beta vulgaris. Plant Physiol. 1949:24:1

38. Flexas J, Ribas-Carbó M, Bota J, Galmés J, Henkle M, Martínez-Cañellas S, Medrano $\mathrm{H}$. Decreased Rubisco activity during water stress is not induced by decreased relative water content but related to conditions of low stomatal conductance and chloroplast $\mathrm{CO}_{2}$ concentration. New Phytol. 2006;172:73-82.

39. Burgess P, Huang B. Growth and physiological responses of creeping bentgrass (Agrostis stolonifera) to elevated carbon dioxide concentrations. Horticulture Res. 2014;1:28-30.

40. Comas LH, Eissenstat DM, Lakso AN. Assessing root death and root system dynamics in a study of grape canopy pruning. New Phytol. 2000;147:171-8.

41. Steponkus PL, Lanphear FO. Refinement of the triphenyl tetrazolium chloride method of determining cold injury. Plant Physiol. 1967;42:1423-6.

42. Zhu X, Chang G, He D, Zhao H, Ma C. Evaluation of new onion varieties using cluster analysis and principal component analysis methods. Gansu Agric Sci. 2014;10:25-8.

43. Huang G, Tong W, Gui Z, Wei L, Zeng Y, Zeng Z, Yin H, Liu G, Zheng J, Yao Y, Li Y. Principal component analysis for physicochemical characteristics of different fruit mulberry cultivars. J Central South Univ Forestry Technol. 2017:37:19-23.

44. Nei M. Analysis of gene diversity in subdivided populations. PNAS. 1973;70: 3321-3

45. Zhang Z, Zeng W, Cai Z, Lai Z, Su Y, Xing G, Wang W, Sun Z, Gai J. Differentiation and evolution among geographic and seasonal ecopopulations of soybean germplasm in southern China. Crop Pasture Sci. 2019;70:121-32 
46. Bradbury PJ, Zhang Z, Kroon DE, Casstevens RM, Ramdoss Y, Buckler ES. TASSEL: software for association mapping of complex traits in diverse samples. Bioinformatics. 2007;23:2633-5.

47. Huang $L$, Yan $H$, Jiang $X$, Yin G, Zhang $X$, Qi X, Zhang Y, Yan Y, Ma X, Peng

$Y$. Identification of candidate reference genes in perennial ryegrass for

quantitative RT-PCR under various abiotic stress conditions. PLoS One. 2014; 9:e93724.

\section{Publisher's Note}

Springer Nature remains neutral with regard to jurisdictional claims in published maps and institutional affiliations.

Ready to submit your research? Choose BMC and benefit from:

- fast, convenient online submission

- thorough peer review by experienced researchers in your field

- rapid publication on acceptance

- support for research data, including large and complex data types

- gold Open Access which fosters wider collaboration and increased citations

- maximum visibility for your research: over $100 \mathrm{M}$ website views per year

At $\mathrm{BMC}$, research is always in progress.

Learn more biomedcentral.com/submissions 